\title{
Caroli Disease: Case report
}

\author{
Buse Yilmaz (Corresponding author) \\ Health Sciences University, Gülhane Medical Faculty, Gulhane Training and Research Hospital, \\ Department of Pediatrics and Health, Ankara, Turkey \\ E-mail: ylmzbuse12@gmail.com \\ Melike Arslan \\ Health Sciences University, Gülhane Medical Faculty, Gulhane Training and Research Hospital, \\ Department of Pediatrics and Health, Ankara, Turkey \\ Necati Balamtekin \\ Health Sciences University, Gülhane Medical Faculty, Gulhane Training and Research Hospital, \\ Department of Pediatrics and Health, Ankara, Turkey
}

\begin{abstract}
Caroli disease is a congenital disorder characterized by multifocal, segmental dilatation or ectasia of large intrahepatic bile ducts. The disease develops due to a remodeling defect, but its molecular pathogenesis is not fully understood. The absence of specific symptoms and signs in Caroli's disease complicates the diagnosis. The magnetic resonance cholangiography (MRCP) is the most sensitive method in diagnosis. Prognosis depends on the degree of liver fibrosis and liver dysfunction and whether or not renal dysfunction is present. In this article, we present a 1.5 -year-old female patient diagnosed with Caroli's disease at the age of 8 months.
\end{abstract}

Key Words: Caroli disease, cystic dilation, children

\section{Special Issue of Health Sciences}

DOI: $10.7176 / \mathrm{JSTR} / 6-03-03$

\section{Caroli Hastalığı: Olgu Sunumu}

Özet

Caroli hastalığı, intrahepatik büyük safra kanallarının multifokal, segmental dilatasyon ve ektazileri ile karakterize oldukça nadir görülen konjenital bir hastalıktır. Hastalık intrahepatik duktal plağın remodelling defektine bağlı gelişmekle birlikte, moleküler patogenezi halen tam olarak anlaşılamamıştır. Hastalığı spesifik semptom ve bulgular olmaması tanıyı zorlaştırır. MRCP tanıda en sensitif yöntemdir. Hastalığın prognozunu karaciğer fibrozisinin, karaciğer fonksiyon bozukluğunun derecesi ve renal fonksiyon bozukluğunun eşlik edip etmemesi belirlemektedir. Bu makalede, 8 aylıkken tanı alan 1,5 yaşındaki Caroli hastası sunulmaktadır.

Anahtar Kelimeler: Caroli hastalığı, kistik dilatasyon, çocuklar

\section{Giriş}

Caroli hastalığ 1 , intrahepatik büyük safra kanallarının multifokal, segmental dilatasyonu veya ektazisi ile karakterize konjenital bir hastalıktır (1). Bu makalede, sekiz aylıkken Caroli hastalığı tanısı alan ve polikliniğimizde takibi devam eden 1,5 yaşında kız hasta sunulmuş ve tartışılmıştır. 


\section{Olgu Sunumu}

Sekiz aylık kız hasta sık üst solunum yolu enfeksiyonu geçirme öyküsü ve huzursuzluk şikayeti ile Çocuk Sağlığı ve Hastalıkları polikliniğinde muayene edilmiş; Hepatomegali saptanması nedeniyle Çocuk Gastroenterolojisi konsültasyonu talep edilmişti. Polikliniğimize getirilen hastanın, aralarında birinci derece akrabalık bulunan 28 yaşında sağ ve sağlıklı anne ile 30 yaşında sağ ve sağliklı babanın yaşayan ikinci çocukları olduğu öğrenildi. Ailede bilinen bir hastalık olmadığı, kardeş ölüm öyküsü olmadığı öğrenildi. Fizik muayenesinde karaciğer kot altında $4 \mathrm{~cm}$ ele geliyordu. Diğer sistem muayeneleri doğald. Laboratuvar incelemelerinde, tam kan sayımında lökosit sayısı: $10.300 / \mathrm{mm}^{3} \mathrm{ml}$, hemoglobin: $10,9 \mathrm{~g} / \mathrm{dL}$, Platelet: $276000 / \mathrm{mm}^{3}$ idi. INR: 1,04 Rutin Biyokimyasal belirteçleri, üre: $28 \mathrm{mg} / \mathrm{dl}$, kreatin: 0,31 mg/dl , AST: $33 \mathrm{IU} / \mathrm{L}$, ALT: $22 \mathrm{IU} / \mathrm{L}$, GGT: $10 \mathrm{IU} / \mathrm{L}$, total blirubin: $0,2 \mathrm{mg} / \mathrm{dl}$, direk bilirubin: $0,05 \mathrm{mg} / \mathrm{dl}$, total protein: $6 \mathrm{~g} / \mathrm{dl}$,albümin: $3,9 \mathrm{~g} / \mathrm{dl}$, sodyum: $139 \mathrm{mmol} / 1$, potasyum: $4,61 \mathrm{mmol} / 1 \mathrm{olarak}$ ölçüldü. Abdomen ultrasonografisinde; KC parankim yapısı ve konturu normal görünümde, KC boyutları midklaviküler hatta cc projeksiyonda $82 \mathrm{~mm}$ ölçülmüştü. Kc parankiminde solid lezyon saptanmamış, her iki karaciğer lobunda çok sayıda kistlere ait anekoik görünümler izlenmişti. Sol lob intrahepatik safra yolları 2,2 mm ile hafif genişlemişti. Ekstrahepatik safra kanalları, hepatik ve portal venler normaldi. Safra kesesi boyutları ve duvar kalınlığı normal olup, kese içinde taşa ait ekojenite izlenmedi. Pankreas, dalak parankim ve boyutları normal görünümde olup, böbrek boyutları ile santral ve parankim ekoları normaldi. Sürrenal gland lojları doğaldı (Resim-1).

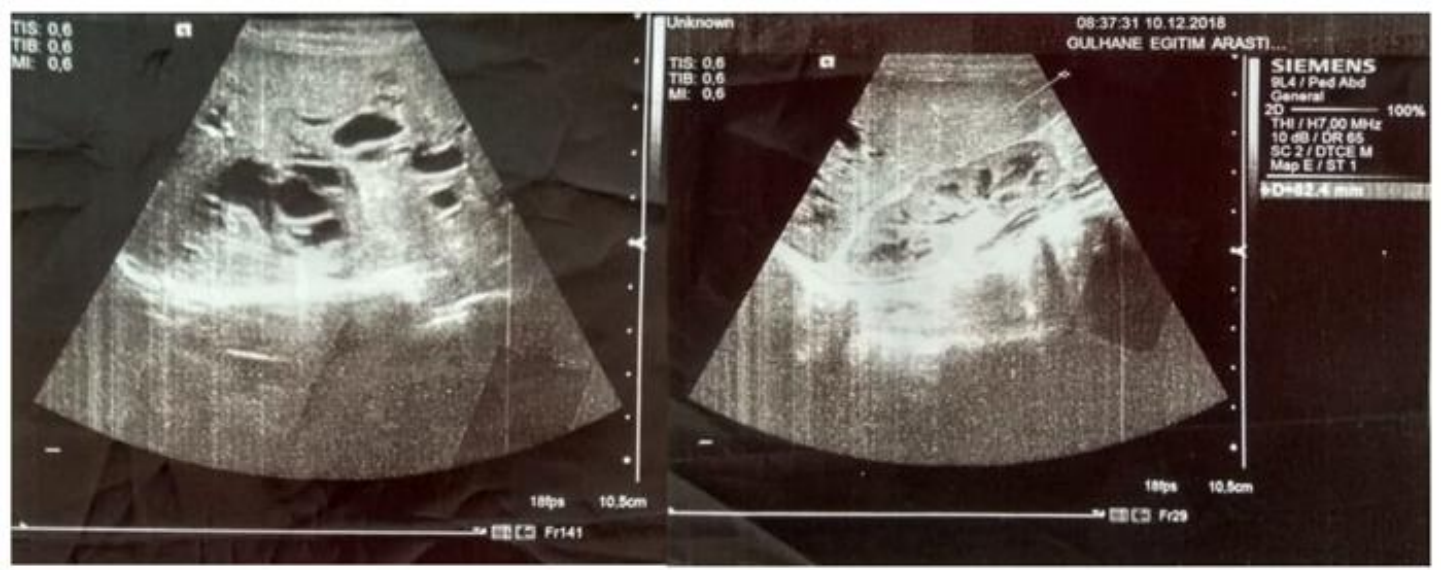

Resim-1: Abdomen ultrasonografide kistlere ait anekoik görünümler

Dinamik üst abdomen MR incelemesinde karaciğer normal boyutlardaydı. Karaciğer parankiminde multiple sayıda intravenöz kontrast madde sonrası kontrastlanmayan kistik lezyonlar mevcuttu (Resim2). MRCP'de bu lezyonların bazılarının safra yolları ile ilişkili olduğu saptanmış olup görünüm Caroli hastalığını düşündürdü. Koledok çapı en geniş yerinde $6,5 \mathrm{~mm}$ olarak ölçüldü. Safra kesesi boyut ve duvar kalınlığı normaldi, kese lümeni doğaldı (Resim-3).

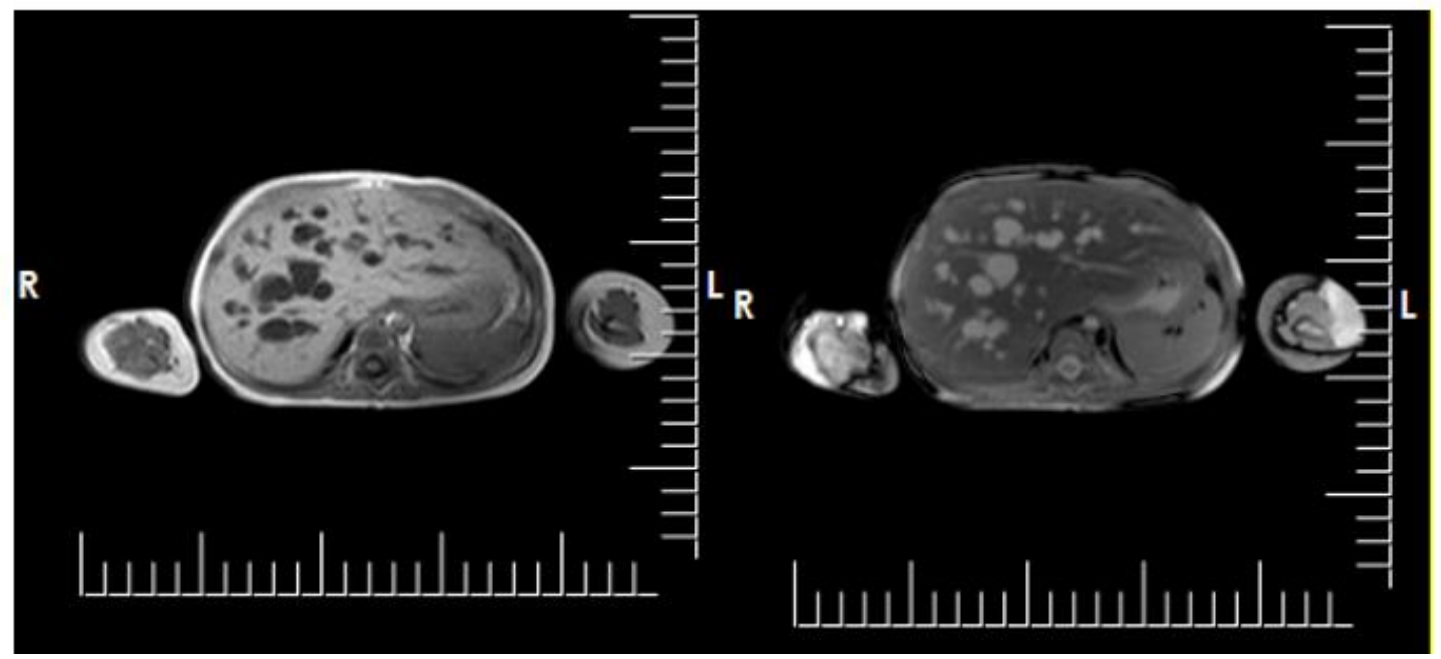

Resim-2: MR incelemede KC' de multiple kistik lezyonlar

15 | P a g e

www.iiste.org 


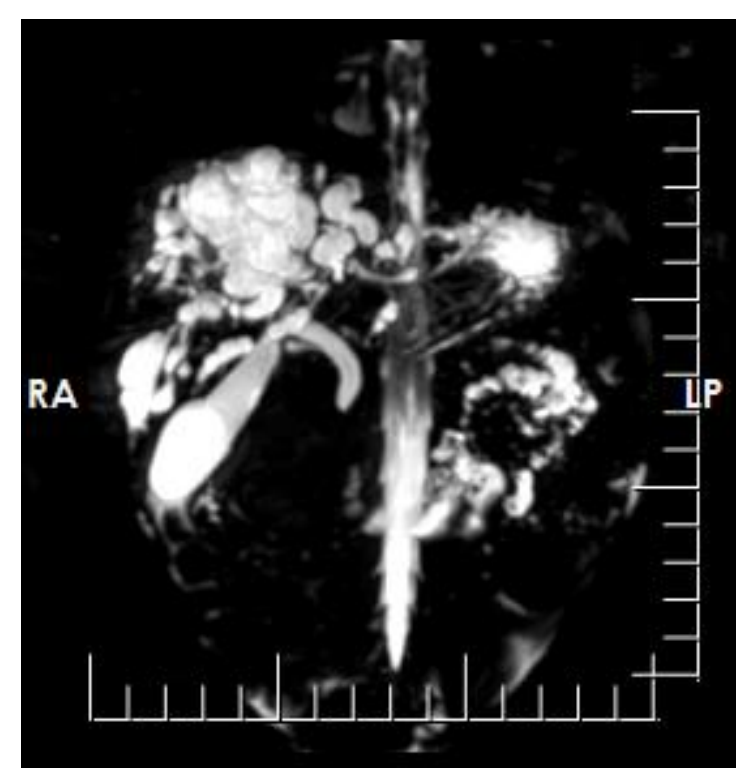

Resim-3: MRCP'de kistler ve safra yolları ile ilişkileri

Hastaya, fizik muayene ve laboratuvar incelemeleri sonucunda Caroli hastalığı tanısı konularak, 15 $\mathrm{mg} / \mathrm{kg} /$ gün dozundan ursodeoksikolik asit tedavisi başlandı. Hasta 3 aylık kontrollerle takip edildi. Hastanın tanı konulduktan sonraki 6. ay kontrolünde yapılan abdomen ultrasonografisinde; intrahepatik ve ekstrahepatik safra kanalları hafif dilate olup koledok proksimal çap1 $5 \mathrm{~mm}$, her iki lobda çok sayıda ince cidarlı anekoik basit kistler izlenmekte olup büyüğü sağ lobda $25 \mathrm{~mm}$ çaplı idi. Sol lobda kistlerin bazılarının safra kanalı komşuluğunda olduğu görüldü. Üç aylık periyotlarla yapılan kontrollerde kolestazı gösteren rutin biyokimyasal belirteçlerinde yükselme görülmedi. Hasta halen üç aylık periyotlarla büyüme gelişme, aşılama gibi pediatrik izlem ile birlikte Caroli hastalığı açısından da yakından izlenmektedir.

\section{Tartışma}

Caroli hastalığı; intrahepatik safra kanallarının multifokal, segmental dilatasyonu, ektazisi ile karakterize, ilk kez 1958' de tanımlanmış bir hastalıktır. Hastalık 2 varyant olarak tanımlanmıştır. Tip 1 Caroli hastalığı olarak da isimlendirilen 'Caroli hastalığı', çok nadir görülen, başka bir karaciğer patolojisinin eşlik etmediği duktal ektazi ve dilatasyonlarla karakterizedir. Tip 2 Caroli hastalığ1 ya da 'Caroli sendromu' ise konjenital hepatik fibrozisin eşlik ettiği duktal dilatasyonlarla karakterizedir. Ayrıca portal hipertansiyon, siroz, özofagus varisleri ile ilişkilidir. Caroli sendromuna otozomal resesif polikistik böbrek hastalığı da eşlik etmektedir (1).

Caroli hastalığ ve Caroli sendromu erkekleri daha az etkiler, erkeklerin kadınlara oranı 1: 1,8 dir. Genellikle ilk iki dekatta tanı alırlar. Caroli hastalığı, Caroli sendromundan çok daha nadir görülmekle beraber, her iki hastalık için prevalans 1/1.000.000' in altındadır. (2) Hastalık gebeliğin 8. haftasında intrahepatik duktal plağın normal embriyolojik şeklinin bozulması, remodelling defekti ve safra kanallarının büyümesine bağlı gelişir (3, 4, 8). Hastalığın moleküler patogenezi tam olarak anlaşılamamıştır. Otozomal resesif polikistik böbrek hastalığına (ARPKD) neden olan 6. kromozom üzerinde lokalize PKHD1 (polikistik böbrek ve hepatik hastalık 1) geninin kodladığı fibrosistin proteininin patogenezde etkili olduğu düşünülmektedir. Fibrosistin, hepatosit growth factor reseptörleriyle yapısal benzerlik göstermektedir, karaciğer ve böbrekte yapısal anormalliklere neden olur. PKHD1 gen mutasyonu dışında birçok gen ve bu genlerin kodladığı proteinlerin hastalığın patogenezinde etkisi olduğu düşünülmektedir ( 5, 6 ). Caroli hastalığı ve Caroli sendromu arasındaki genetik köken farklılığı henüz aydınlatılamamıştır. Ayrıca Galen malformasyonu ve Caroli hastalığı birlikteliğinin bidirildiği bir çalışmada, VEGF overekspresyonunun her iki hastalığın gelişiminde etken olduğuna dair hipotezler mevcuttur (7).

Klinik belirtiler herhangi bir yaşta ortaya çıkabilir. En sık süt çocukları ve genç yetişkinlik döneminde tanı konulur. Hastalar sağ üst kadran ağrısı, abdominal distansiyon, ateş, anoreksi, sarılık, yorgunluk, bulant1, kusma , ödem, abse oluşumu, hepatomegali gibi semptom ve bulgularla prezente olabilir veya 
asemptomatik olabilirler. Caroli hastalağına spesifik bir semptom veya bulgu olmaması tanıy zorlaştırmaktadır $(\mathbf{1}, \mathbf{3})$.

Hastalarda, kolanjit ataklarında transaminaz yüksekliği, hiperbilirubinemi, lökositoz ayrıca pansitopeni, anemi gibi laboratuvar bulguları görülebilir. 30 hasta üzerinde yapılan bir çalışmada anemi, lökopeni, trombositopeninin Caroli sendromunda daha sık görüldüğü gösterilmiştir(1). Hastalar fizik muayane ve laboratuvar testlerinin 1 şı̆̆ında değerlendirildikten sonra görüntüleme yöntemlerine başvurulmalıdır. Tanıda en faydalı görüntüleme yöntemleri MRCP ve BT’ dir (1). Kesin tanı ve hastalığın şiddeti MRCP, PTK ve ERCP ile belirlenir (3). İlk aşamada ultrasonografi ile karaciğerde duktal dilatasyonlar izlenebilir. BT ile kistik değişikliklerin boyutları ve lokalizasyonları, MRCP ile kistlerin safra yollarıyla ilişsisi ortaya konabilir $(\mathbf{8}, \mathbf{9})$. İnvazif yöntemlerden komplikasyon riski nedeniyle mümkün olduğunca uzak durulmalıdir (1).

Bizim olgumuza; ultasonografisinde multiple kistler görülmesi üzerine yapılan BT ve MRCP' de Todani klasifikasyonuna göre Caroli hastalığına özgü olan tip V biliyer kistler (8) görülmesi, Caroli sendromu ile ilişkili olan polikistik böbrek hastalığ 1 , hepatik fibrozis gibi başka bir hepatik patoloji olmaması üzerine Caroli hastalı̆̆ tanısı konuldu.

Erken tanı ve hastalığın tipi prognoz açısından oldukça önemlidir (1). Prognoz, hastalığın şiddetine yani karaciğer fibrozisi ve karaciğer fonksiyon bozukluğu derecesine ve renal disfonksiyonların eşlik edip etmemesine bağlıdır. Hastalığın başlangıcında karaciğer fonksiyonları bozuk değildir. Tekrarlayan enfeksiyonlar ve kolanjit ataklarına bağlı karaciğer hasarı gelişebilir. Safra taşı ve karaciğer absesi gelişimi de bildirilmiştir (3).

Caroli sendromunda kolanjiokarsinoma gelişme riski artmıştır. Caroli sendromu tanılı hastaların \% 2,5 17,5 'unda kolanjiokarsinom geliştiği bildirilmiştir (1). Risk artışının nedeninin; duktal staz ve safra asitlerinin konsantrasyonunun artışı olabileceği düşünülmektedir.

Tedavi daha çok destek tedavisidir ve asıl amaç kolanjit ataklarını önlemek için biliyer drenajı sağlamaktır. Kolanjit ve sepsis antibiyoterapi ile tedavi edilirken, kronik kolestazda yağda çözünen vitamin desteği verilebilir. Özofagus varisi gelişen hastalarda profilaktik nonselektif beta blokör kullanılır. Safra taşına bağlı komplikasyonları azaltmak amacıyla ursodeoksikolik asit tedavisi (10-20 $\mathrm{mg} / \mathrm{kg} / \mathrm{gün}$ ) kullanılabilir. Ursodeoksikolik asit safra akışını arttırır, stazı azaltarak taş oluşumunu azaltır $(\mathbf{1 0}, \mathbf{1 1})$. Hastalık tek lobta sinırlıysa hepatektomi faydalı olabilir. Kolanjiokarsinoma riski yüksek olduğundan karaciğer nakli gerekebilir. (1)

Bizim olgumuz erken dönemde tanı alarak, erken dönemde takibe girdi. Tanı ve takip döneminde de laboratuvar tetkiklerinde anormal bulguya rastlanmadi. Hasta ursodeoksikolik asit tedavisiyle takip ediliyor. Takip süresince kolanjit atağı veya portal hipertansiyon bulgusu olmadı.

\section{Sonuç}

Caroli hastalığı çok nadir görülen ve genellikle tanısı ileri yaşlarda konulan bir hastalıktır. Erken tanı konulması, bu hastalarda hastalıkla ilişsili komplikasyonların erken tanınmasına ve zamanında tedavi edilmesine fursat vereceği için çok değerlidir. Hepatomegaliyle getirilen infantlarda, hepatomegalinin çok nadir bir nedeni olan Caroli hastalığı da akla getirilmeli ve zamanında tanı konulmalıdır.

\section{Kaynaklar}

[1] Wang ZX, Li YG, Wang RL, Li YW, Li ZY, Wang LF, Yang HY, Zhu Y, Wang Y, Bai YF, He TT, Zhang XF, Xiao XH. Clinical classification of Caroli's disease: an analysis of 30 patients. HPB (Oxford). 2015 Mar;17(3):278-83.

[2] Cabral Correia P, Morgado B. Caroli's Disease as a Cause of Chronic Epigastric Abdomianl Pain: Two Case Reports and Brief Review of the Literature. Cureus. 2017 Sep 20;9(9):e1701.

[3] Ali KARAMAN, Doğan NASIR BİNİĊ, İhsan DORU. Caroli hastalığı: Bir olgu sunumu . Göztepe tıp dergisi 2009 24(2):92-94.

[4] F Keane, M Wilkinson, S Qureshi, C Reid, A Baker, G Mieli-Vergani. Neonatal presentation of Caroli's disease Arch Dis Child Fetal Neonatal Ed. 1997 Sep; 77(2): F145-F146.

[5] Ward CJ, Hogan MC, Rossetti S, Walker D, Sneddon T, Wang X, Kubly V, Cunningham JM, Bacallao R, Ishibashi M, Milliner DS, Torres VE, Harris PC. The gene mutated in autosomal recessive polycystic kidney disease encodes a large, receptor-like protein. Nat Genet. 2002 Mar;30(3):259-69.

17 | $P$ a g e 
[6] Onuchic LF, Furu L, Nagasawa Y, Hou X, Eggermann T, Ren Z, Bergmann C, Senderek J, Esquivel E, Zeltner R, Rudnik-Schöneborn S, Mrug M, Sweeney W, Avner ED, Zerres K, Guay-Woodford LM, Somlo S, Germino GG. PKHD1, the polycystic kidney and hepatic disease 1 gene, encodes a novel large protein containing multiple immunoglobulin-like plexintranscription-factor domains and parallel beta-helix 1 repeats. Am J Hum Genet. 2002 May;70(5):1305-17.

[7] Dominik Grieb, Axel Feldkamp, Thomas Lang, Michael Melter, Christian Stroszczynski, Friedhelm Brassel and Dan Meila. Caroli Disease Associated With Vein of Galen Malformation in a Male Child. Pediatrics July 2014, 134 (1) e284-e288.

[8] Levy AD, Rohrmann CA Jr, Murakata LA, Lonergan GJ. Caroli's disease: radiologic spectrum with pathologic correlation. AJR Am J Roentgenol. 2002 Oct;179(4):1053-7.

[9] Lefere M, Thijs M, De Hertogh G, Verslype C, Laleman W, Vanbeckevoort D, Van Steenbergen W, Claus F. Caroli disease: review of eight cases with emphasis on magnetic resonance imaging features. Eur J Gastroenterol Hepatol. 2011 Jul;23(7):578-85.

[10] Taylor AC, Palmer KR. Caroli's disease. Eur J Gastroenterol Hepatol. 1998 Feb;10(2):105-8

[11] Ros E, Navarro S, Bru C, Gilabert R, Bianchi L, Bruguera M Ursodeoxycholic acid treatment of primary hepatolithiasis in Caroli's syndrome. Lancet. 1993 Aug 14;342(8868):404-6. 